\title{
Incremental Spiral CT
}

National Cancer Institute

\section{Source}

National Cancer Institute. Incremental Spiral CT. NCI Thesaurus. Code C19914.

A type of computed tomography in which the patient is moved through the scanner in increments rather than in a continuous fashion. 